\title{
CAMBIOS RECIENTES EN EL CAUCE Y LA LLANURA DE INUNDACIÓN DEL ÁREA DE CONFLUENCIA ARAGÓN-ARGA (NAVARRA)
}

\author{
Vanesa Acín Naverac \\ Ecoter, Ecología y Territorio S.C. \\ info@ecoter.como.es \\ Elena Díaz Bea
}

Dpto. de Geografía, Prehistoria y Arqueología, Universidad del País Vasco

\section{David Granado García}

Ecoter, Ecología y Territorio S.C.

\section{Askoa Ibisate González de Matauco}

Dpto. de Geografía, Prehistoria y Arqueología, Universidad del País Vasco askoa.ibisate@ehu.es

\section{Alfredo Ollero Ojeda}

Dpto. de Geografía y Ordenación del Territorio, Universidad de Zaragoza aollero@unizar.es

\begin{abstract}
Resumen: Se ha desarrollado un análisis diacrónico de la evolución del sistema fluvial empleando herramientas SIG. Mediante fotografías aéreas georreferenciadas y ortoimágenes se ha cuantificado y cartografiado tanto la evolución del trazado del cauce como las modificaciones de los usos de suelo en la llanura de inundación. Los cambios más significativos se observan entre 1966 y 1992. Se han perdido superficies naturales y se ha estabilizado el cauce, de forma drástica a partir de los años 80 , aunque algunos meandros del río Aragón mantienen dinámica. Los sistemas de regulación, las defensas locales en cada meandro y la canalización del Arga son responsables del deterioro de la dinámica natural y del proceso de estabilización y simplificación geomorfológica.
\end{abstract}

Recibido: 9-11-10. Aceptado: 3-11-11. 
Palabras clave: geomorfología fluvial, cauce, llanura de inundación, confluencia, río Aragón, río Arga.

\begin{abstract}
Channel and floodplain changes in the Aragón-Arga river confluence. A diachronic analysis of the evolution of river system using GIS tools has been developed. With georeferenced aerial photographs and orthoimages, has been quantified and mapped both the evolution of channel planform as changes in land uses in the floodplain. The most significant changes are observed between 1966 and 1992 . Natural surfaces have been lost and the channel has been stabilized, dramatically from the 80, although some meanders in Aragón river maintain dynamics. Regulatory systems, local defences for each bend and the channelization of Arga are responsible for the natural behaviour deterioration and the process of stabilization and geomorphic simplification.
\end{abstract}

Keywords: fluvial geomorphology, channel, floodplain, confluence, Aragón river, Arga river.

\title{
1. Introducción
}

Los ríos aluviales de llanura destacan por sus activos procesos de dinámica fluvial. El curso medio del río Ebro y los cursos bajos de sus principales afluentes constituyen algunos de los ejemplos más interesantes de la Península Ibérica.

El área de estudio se centra en la confluencia en el curso bajo del río Aragón con su principal afluente, el río Arga, a tan sólo $9 \mathrm{~km}$ de la desembocadura en el Ebro. La cuenca del Aragón, con $8.604 \mathrm{~km}^{2}$, es la tercera de mayor superficie en la cuenca del Ebro. De acuerdo con datos de la Confederación Hidrográfica del Ebro, el río Aragón es el afluente más caudaloso del Ebro tras el Segre: en la confluencia aporta $114,6 \mathrm{~m}^{3} / \mathrm{s}$, duplicando aguas abajo el caudal del Ebro, que registra $234,1 \mathrm{~m}^{3} / \mathrm{s}$ en Castejón. La cuenca del Arga conforma el 32\% de la superficie total de la cuenca del Aragón, y el caudal de este río $\left(50,1 \mathrm{~m}^{3} / \mathrm{s}\right)$ supone en la confluencia del Aragón el $43 \%$ del caudal total de los dos ríos.

Los ríos Arga y Aragón son sistemas de gran complejidad geomorfológica y ambiental que han sufrido perturbaciones recientes por intervención antrópica. Sus cursos bajos se caracterizaban en la primera mitad del siglo XX por un trazado de transición trenzado-meandriforme, con amplias curvas y sectores con división en varios brazos, una vasta extensión de barras activas y gran diversidad de unidades 
geoecológicas. Los cambios de trazado del cauce menor eran muy frecuentes. La introducción de estructuras de regulación en las cuencas, los cambios de usos del suelo, la ampliación de los regadíos, la invasión del espacio fluvial y el desarrollo de defensas para evitar la movilidad y la erosión de las orillas generaron, entre los años 50 y los 80 del siglo XX, un proceso de simplificación, estabilización y estrechamiento del cauce.

En la cuenca del Aragón entró en funcionamiento en 1960 el embalse de Yesa (capacidad total de 446,9 $\mathrm{hm}^{3}$ ), con usos de abastecimiento, riego y energía hidroeléctrica, pero con claras afecciones al sistema fluvial aguas abajo, como la reducción del caudal líquido y sólido, la alteración del régimen hidrológico y la laminación de las crecidas, que con el tiempo han ido reduciendo notablemente la dinámica y complejidad del cauce. El actual recrecimiento de la presa de Yesa para duplicar la capacidad del embalse y la reciente construcción del embalse de Itoiz en 2003 (capacidad total de $418 \mathrm{hm}^{3}$ ) en el río Irati, principal afluente del Aragón inmediatamente aguas abajo de Yesa y que renaturalizaba la dinámica del mismo, agravarán inevitablemente estos efectos. No en vano la superficie de cuenca afectada por ambos embalses supone el 31,1\% respecto a la superficie total de la cuenca del Aragón.

Por otra parte, en el curso bajo del Aragón a partir de la década de los 60 del siglo $\mathrm{XX}$ se generalizaron las defensas de margen y pequeños rellenos y cortas artificiales, y durante la última década del mismo siglo se construyeron tres minicentrales hidroeléctricas (Santacara, Mélida y Caparroso) que cortocircuitan otros tantos meandros, reduciendo considerablemente la movilidad lateral del cauce y agravando el proceso de incisión que ya estaba experimentando el cauce ante los efectos de los embalses. También se han efectuado dragados de diversa localización y distintas fechas. En el curso bajo del río Arga el impacto más relevante es la canalización de los últimos 13,3 $\mathrm{km}$ de longitud cortando los meandros que describía y creando un cauce artificial y poco sinuoso; la obra se inició en la década de los 60 del siglo XX en la zona más cercana a la confluencia y terminó en los años 80 en Falces.

Como resultado, los bajos Aragón y Arga son hoy cursos meandriformes con muy escasa dinámica. Este proceso es idéntico al registrado durante el mismo periodo de tiempo en el curso medio del Ebro, de caracteres geomorfológicos similares (Ollero, 1992, Cabezas et al., 2009, Magdaleno, 2011). La dinámica fluvial de estos cursos de llanura fue descrita en varios trabajos precedentes (Ben Ayed, 1993; El Moujahid, 1993; Jimeno, 1993, 1996, Bescos, 2003; Bescós y Camarasa, 2004).

El objetivo del presente artículo es comprobar con nuevos registros fotográficos y herramientas SIG el proceso de estabilización y simplificación de una dinámica geomorfológica progresivamente afectada por la regulación hídrica, aportándose una 
información actualizada y una nueva cartografía de detalle cuya leyenda es aplicable a otros tramos fluviales de interés.

Se ha seleccionado como área de estudio la más próxima a la confluencia de los ríos Arga y Aragón (figura 1), subdividiéndose en tres sectores de caracteres básicos similares pero de diferente dinámica: a) río Aragón desde Caparroso hasta la zona de confluencia, de 19,95 km de longitud, b) río Arga desde Falces hasta la zona de confluencia, de $14,6 \mathrm{~km}$, c) la propia zona de confluencia y un corto tramo aguas abajo, de $4,4 \mathrm{~km}$.
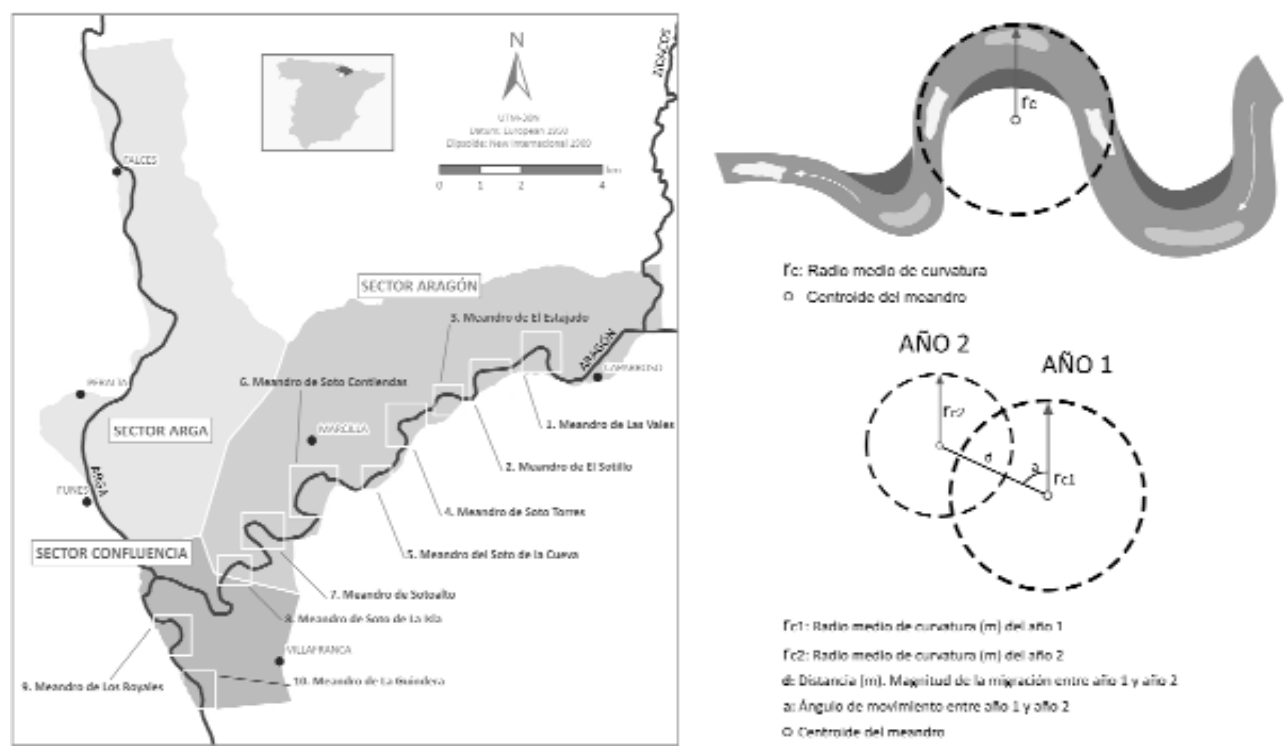

Figura 1. Área de estudio (izda.), incluyendo los diez meandros analizados en el río Aragón y los parámetros medidos en los mismos (dcha.).

Los cambios analizados constituyen una base muy útil para comprender las variaciones que se han producido en ambas cuencas, para conocer las áreas de mayor calidad hidromorfológica, para definir los sectores de mayor riesgo de erosión y de inundación y para plantear acciones de ordenación territorial. En este sentido resulta muy interesante la figura del Territorio Fluvial, un espacio delimitado por criterios geomorfológicos, ecológicos e históricos, donde ha de favorecerse la dinámica fluvial y evitar los usos antrópicos que la restrinjan. 


\section{Metodología}

Se ha realizado un análisis diacrónico mediante fotografías aéreas georreferenciadas y ortoimágenes que ha permitido cuantificar y cartografiar la evolución del cauce y de los usos de suelo en la llanura de inundación. Se han seleccionado y utilizado fotogramas aéreos verticales de los siguientes vuelos y fechas:

- 1927: CETFA para la Confederación Hidrográfica del Ebro, a escala aproximada 1:9000. Recoge todo el tramo de estudio del río Aragón y el Arga aguas abajo de Peralta.

- 1956: Servicio Geográfico del Ejército, a escala aproximada 1:10000.

- 1966: Gobierno de Navarra, a escala 1:18000.

- 1984: Instituto Geográfico Nacional, a escala aproximada 1:30000.

- 1992: un vuelo realizado por GEOCART para la Confederación Hidrográfica del Ebro a escala 1:8000 cubre los ríos Aragón e Irati; otro vuelo del Gobierno de Navarra realizado en septiembre a 1:20000 engloba todo el Aragón más el Arga aguas abajo de Falces.

- 2006: ortoimágenes del Plan Nacional de Ortofotografía Aérea (PNOA), a escala 1:5000.

- 2008: vuelo LiDAR a escala 1:1000 de la confluencia de los ríos Arga y Aragón, realizado en octubre de 2008 por TRACASA para el Gobierno de Navarra.

Las fotos fueron georreferenciadas sobre bases topográficas y con la ayuda de las imágenes del PNOA (2006). A cada una de las imágenes se le asignó la proyección del sistema de coordenadas European Datum 1950 UTM Zona 30N, que abarca toda el área de estudio. El proceso de georreferenciación se realizó con mucho detalle para poder analizar los cambios de forma precisa con las herramientas SIG.

Para el análisis de detalle de los cambios de usos de suelo se establecieron 8 categorías, que se cartografiaron en 5 de los 7 vuelos utilizados (1927, 1956, 1966, 1992, 2008):

- Cauce: lámina de agua de los cauces del Arga y Aragón en el momento de la imagen.

- Barras: depósitos sedimentarios sin vegetación.

- Vegetación pionera y praderas: vegetación herbácea colonizadora y praderas.

- Vegetación de ribera: árboles y arbustos de ribera.

- Repoblaciones: plantaciones de chopos.

- Cultivos

- Núcleos de población

- Otras zonas antropizadas: áreas taladas, de extracciones de áridos, movimientos de tierras, polígonos industriales, etc. 
Para el análisis de los cambios de trazado en el cauce se ha editado la lámina de agua que presenta el cauce en todos los vuelos mencionados, comprobándose previamente que los caudales circulantes eran parecidos en todos los casos, y se han cuantificado dichos cambios.

El análisis de los usos del suelo de la llanura de inundación se realizó calculando las superficies de las distintas categorías en los diferentes años estudiados, así como por los tres sectores funcionales, de cara a conocer la evolución de cada una de las categorías sobre la llanura de inundación.

Con el fin de conocer la superficie movilizada se calculó el área modificada entre la orilla del cauce en la fotografía de inicio del periodo y la misma orilla del cauce en la fotografía final del período (Downward et al., 1994). También se obtuvo la superficie activa, que incluye el trazado del cauce de cada par de años analizado y la superficie que queda entre ambos trazados.

De forma paralela, se ha realizado un análisis de la migración de diez meandros (figura 1): Las Vales, El Sotillo, El Estajado, Soto Torres, Soto de la Cueva, Soto Contiendas, Sotoalto, La Isla, Los Royales y La Guindera, y de su futura evolución a partir de la metodología de Lagasse et al. (2004), basada en los cambios del centroide de cada meandro, de su radio de curvatura y del ángulo de migración entre las fechas estudiadas. Igualmente se clasificó el tipo de cambio o evolución en cada meandro y en cada uno de los períodos estudiados.

\section{Resultados}

\subsection{Cambios en los usos del suelo de la llanura de inundación}

Los cambios de usos de suelo durante el período estudiado han sido muy marcados. Destaca la pérdida de banda activa (cauce y barras), especialmente la disminución del material aluvial movilizable, lo que simplifica el cauce. Por otra parte se detecta el aumento considerable de plantaciones de Populus sp., en detrimento de la vegetación de ribera, así como el de núcleos de población y superficies antropizadas. Es posible marcar un punto de inflexión muy claro entre los años 1966 y 1992 (figura 2 ), pues en ese lapso temporal se instalaron buen número de repoblaciones y defensas, lo que conllevó una reducción considerable de las superficies naturales (cauce, barras, vegetación pionera y de ribera), no así de las otras categorías (cultivos, repoblaciones, núcleos y zonas antropizadas), que aumentan su representación. 


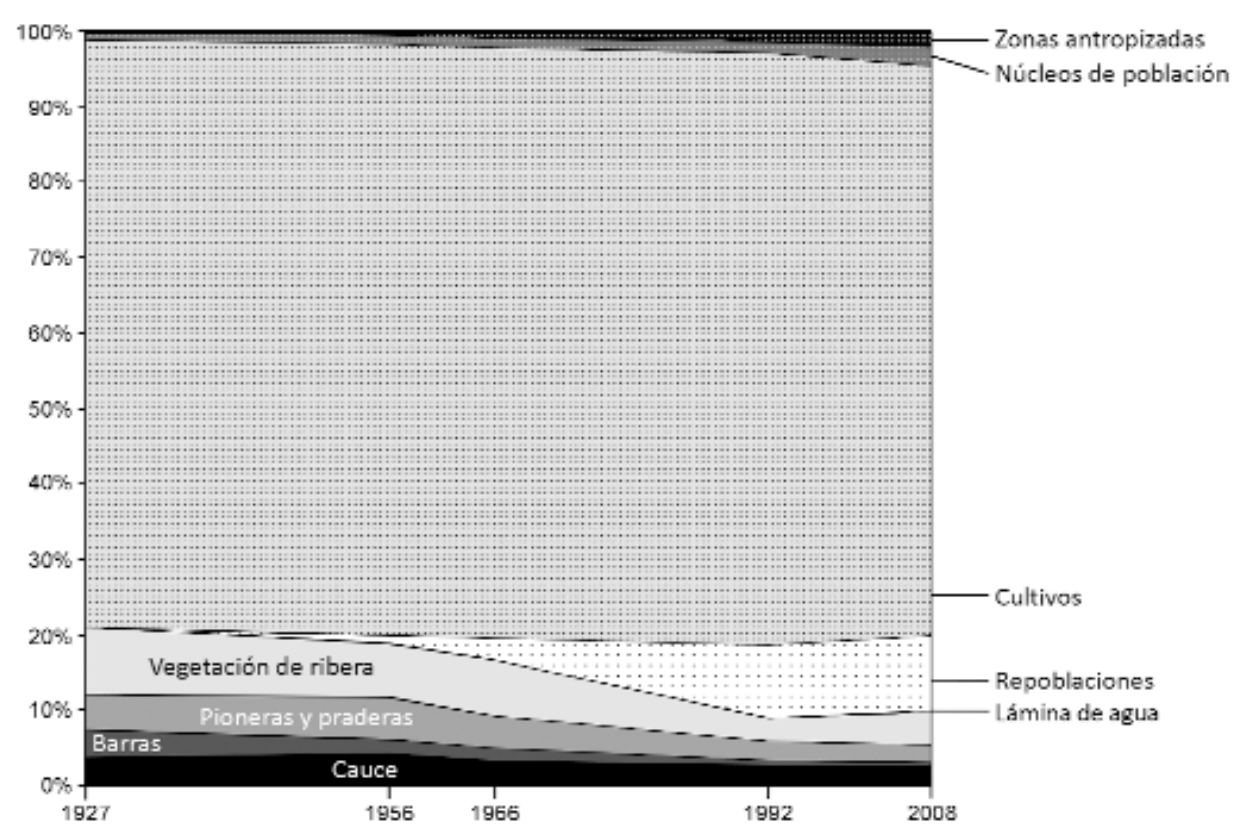

Figura 2. Evolución de las superficies de usos del suelo en porcentajes respecto a la extensión total de la llanura de inundación en el conjunto de los tres sectores.

Las superficies naturales ocupaban en 1927 un $20,92 \%$ de la llanura de inundación, mientras que en 2008 tan sólo suponen un 9,94\% (tabla 1). Los cambios más significativos se inician en la década 1956-1966, momento en el cual se produce un cambio drástico en el funcionamiento hidrológico de la cuenca, con la puesta en marcha del embalse de Yesa, y se consolidan en el periodo 1966-1992, con la proliferación de defensas y canalizaciones que limitan la dinámica fluvial e impiden la movilidad del cauce en los tres sectores analizados (figuras 3, 4 y 5). Los cambios son especialmente significativos en el área de confluencia (figura 6). La estabilización de la zona de la confluencia es una respuesta a las actuaciones en el sistema fluvial aguas arriba, como la simplificación progresiva del cauce del Aragón por el efecto del embalse de Yesa y por acciones puntuales como las cortas artificiales de los meandros del soto de la Lobera y el Estajado, la corta natural pero inducida del Soto Torres, y por defensas y dragados. En el caso del Arga se debe a la canalización y corta artificial de meandros. Incluso la propia confluencia ha sido fijada mediante escollera y las barras se han dragado periódicamente para aumentar la sección de desagüe. Una consecuencia de la estabilización del cauce en este punto es la invasión del corredor ribereño por plantaciones de chopos, con la consiguiente pérdida de diversidad de antiguos cauces y la vegetación ribereña asociada a ellos. 
Tabla 1. Evolución de las superficies de usos de suelo en el ámbito de estudio en valores porcentuales

\begin{tabular}{|l|c|c|c|c|c|}
\hline Categorias & 1927 & 1956 & 1966 & 1992 & 2008 \\
\hline Cauce & 3,87 & 4,18 & 3,31 & 2,77 & 2,60 \\
Barras & 3,49 & 2,20 & 1,64 & 0,57 & 0,57 \\
Pioneras y praderas & 4,66 & 5,53 & 4,28 & 2,60 & 2,28 \\
Vegetación de ribera & 8,91 & 7,82 & 7,58 & 3,11 & 4,48 \\
Repoblaciones & 0,03 & 0,40 & 2,69 & 9,61 & 10,01 \\
Cultivos & 77,99 & 78,20 & 78,21 & 78,34 & 75,47 \\
Núcleos de población & 0,79 & 1,37 & 1,52 & 1,80 & 2,64 \\
Áreas degradadas & 0,26 & 0,31 & 0,76 & 1,22 & 1,94 \\
\cline { 2 - 6 } Total & 100 & 100 & 100 & 100 & 100 \\
\hline
\end{tabular}

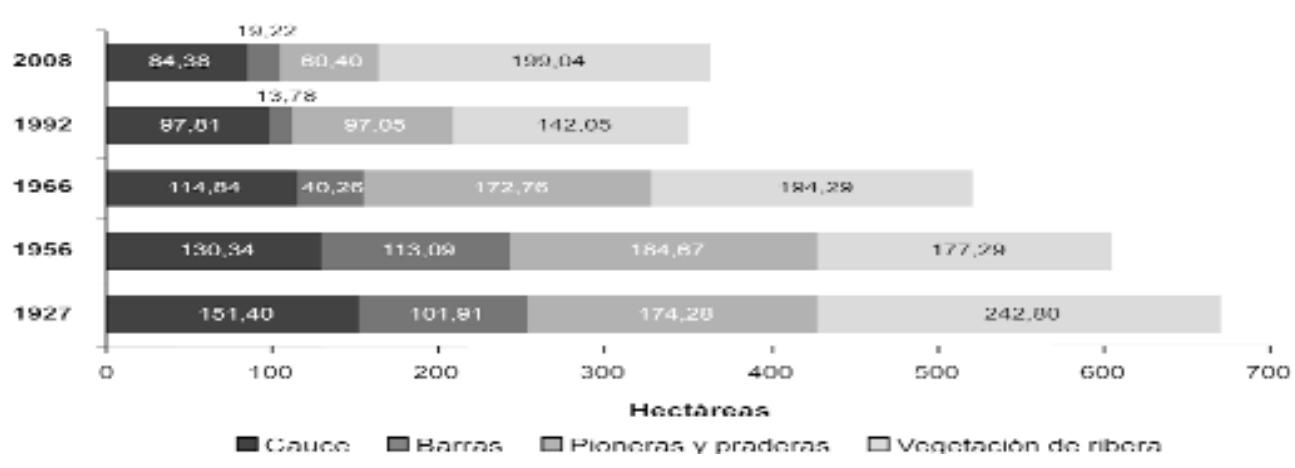

Figura 3. Evolución de las superficies naturales en el sector Aragón en valores absolutos (ha).

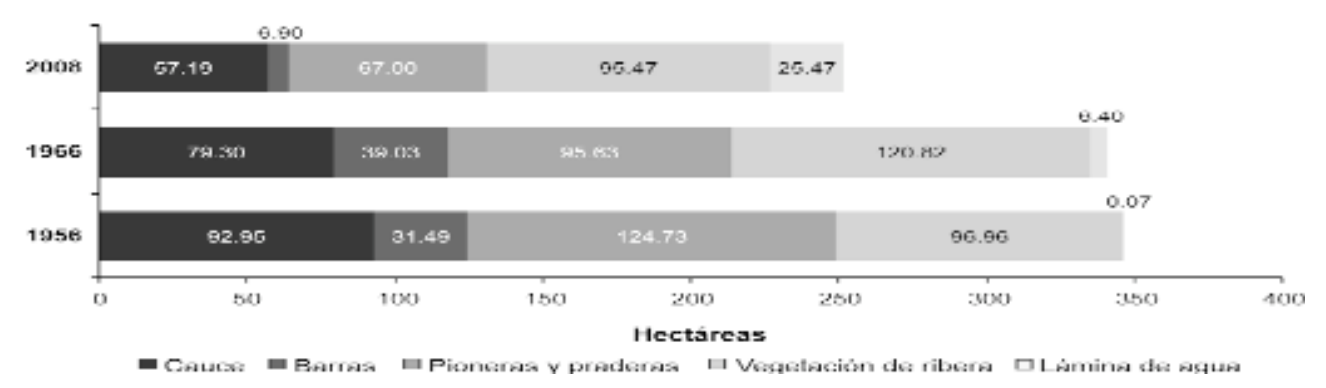

Figura 4. Evolución de las superficies naturales en el sector Arga en valores absolutos (ha). 


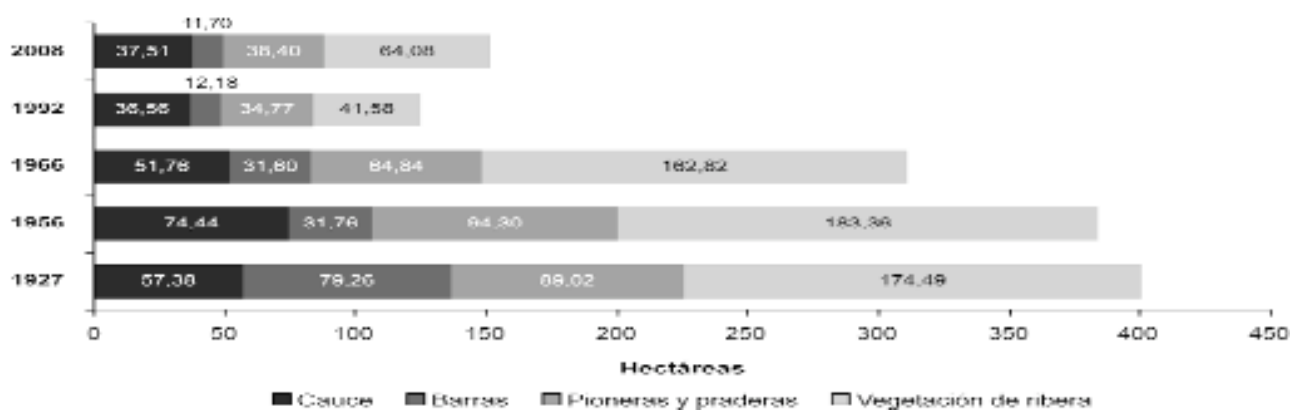

Figura 5. Evolución de las superficies naturales en el sector confluencia en valores absolutos (ha).

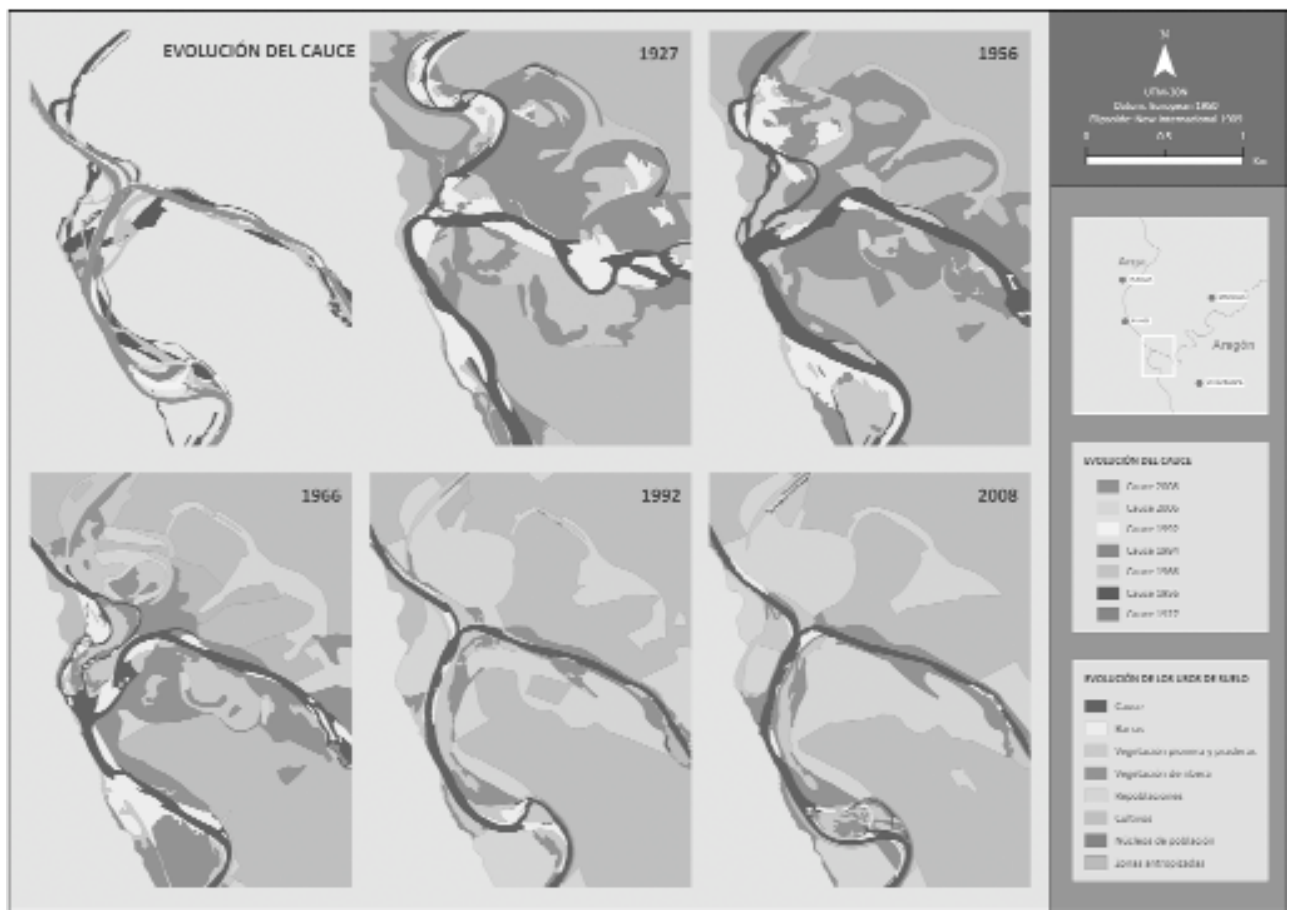

Figura 6. Ejemplo de cartografía diacrónica del trazado del cauce y de usos del suelo en la llanura de inundación en la confluencia de los ríos Arga y Aragón. 


\subsection{Cambios en el trazado del cauce}

Destaca una reducción progresiva de las superficies movilizadas, aunque con un ligero repunte en el último período, provocado por cambios en el sector de confluencia. La superficie movilizada media anual es de 16,20 ha en el primer período y se reduce a 6,65 ha en el último período. Por su parte, la superficie activa era de 358,09 ha en el período 1927-1956, mientras que en el período 2006-2008 alcanza tan sólo 89,96 ha. En total, la superficie activa se ha reducido en 268,12 ha a lo largo de 81 años, lo que refleja una pérdida de superficie activa de 3,31 ha anuales (figura 7). La superficie movilizada en el Arga es mínima a partir de la canalización que limita la migración lateral del cauce, ejecutada a mediados de los años 80.
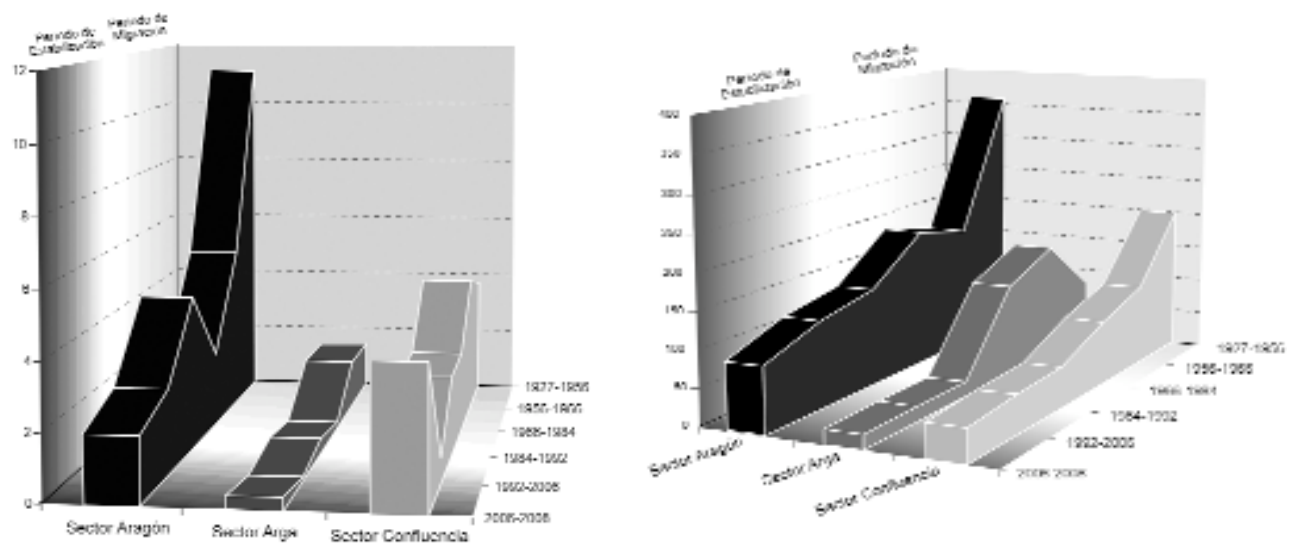

Figura 7. Evolución de la superficie movilizada media anual (a) y de la superficie activa (b) por períodos (en ha).

En lo referente a la dinámica de meandros, en el denominado periodo de migración, desde 1927 hasta 1984, la distancia de migración es cada vez más reducida, presentando valores desde casi $700 \mathrm{~m}$ entre 1927 y 1957 hasta inferiores a $100 \mathrm{~m}$ entre 1967 y 1984. En el periodo de estabilización, de 1984 a 2008, la mitad de los meandros (Soto Torres, Soto Contiendas, Sotoalto, La Isla y la Guindera) apenas muestran migración, aunque el resto presentan una recuperación de la distancia media en torno a los 147,9 metros en los dos últimos años. 
Tabla 2. Distancia media del cambio anual.

\begin{tabular}{|c|c|}
\hline $1927-1956$ & $15,04 \mathrm{~m}$ \\
$1956-1966$ & $12,08 \mathrm{~m}$ \\
$1966-1984$ & $10,76 \mathrm{~m}$ \\
$1984-1992$ & $6,91 \mathrm{~m}$ \\
$1992-2006$ & $5,34 \mathrm{~m}$ \\
$2006-2008$ & $7,91 \mathrm{~m}$ \\
\hline
\end{tabular}

En cuanto al radio de curvatura de los meandros, en el periodo de migración va siendo cada vez más reducido y en el de estabilización presenta una ligera variación positiva, la cual es insignificante porque se ha dado en el breve periodo de los dos últimos años.

Los tipos de cambio son variados. En términos generales en el primer periodo predominan la traslación, expansión y extensión, mientras que en el segundo la reducción y la estabilización. Algunos cambios detectados son artificiales, como cortas (el Sotillo, el Estajado) y retranqueo de márgenes (Las Vales).

\section{Discusión}

Se ha constatado que la dinámica geomorfológica de los ríos Arga y Aragón se ha visto reducida de forma contundente a lo largo de los últimos 80 años. Esto es debido principalmente a la humanización de la llanura de inundación y a los cambios que se han producido en la cuenca. Las superficies de usos de suelo se han visto muy modificadas desde 1927, destacando un aumento de las superficies no naturales (cultivos, repoblaciones, núcleos urbanos y zonas antropizadas), en detrimento de las naturales (cauce, barras y vegetación natural). El cauce en ambos ríos ha perdido actividad, por la instalación de sistemas defensivos en ambos cursos a partir de la década de los 60, por la canalización del Arga en los 80 y por la puesta en explotación de los embalses, en especial en el caso del Aragón. Así, la estabilización definitiva del cauce se produce en los años ochenta.

El análisis de las tasas de migración lateral del cauce constituye un indicador fundamental para evaluar la dinámica fluvial (Hickin y Nanson, 1984). Los patrones de migración observados en los cursos bajos del Aragón y el Arga, y la evolución de los mismos, son muy similares a los cuantificados por Uribelarrea (2008) en los ríos Manzanares, Jarama y Tajo. La distancia media de cambio anual en los meandros estudiados en el periodo $1927-56$ es muy similar a la registrada en el curso medio del río 


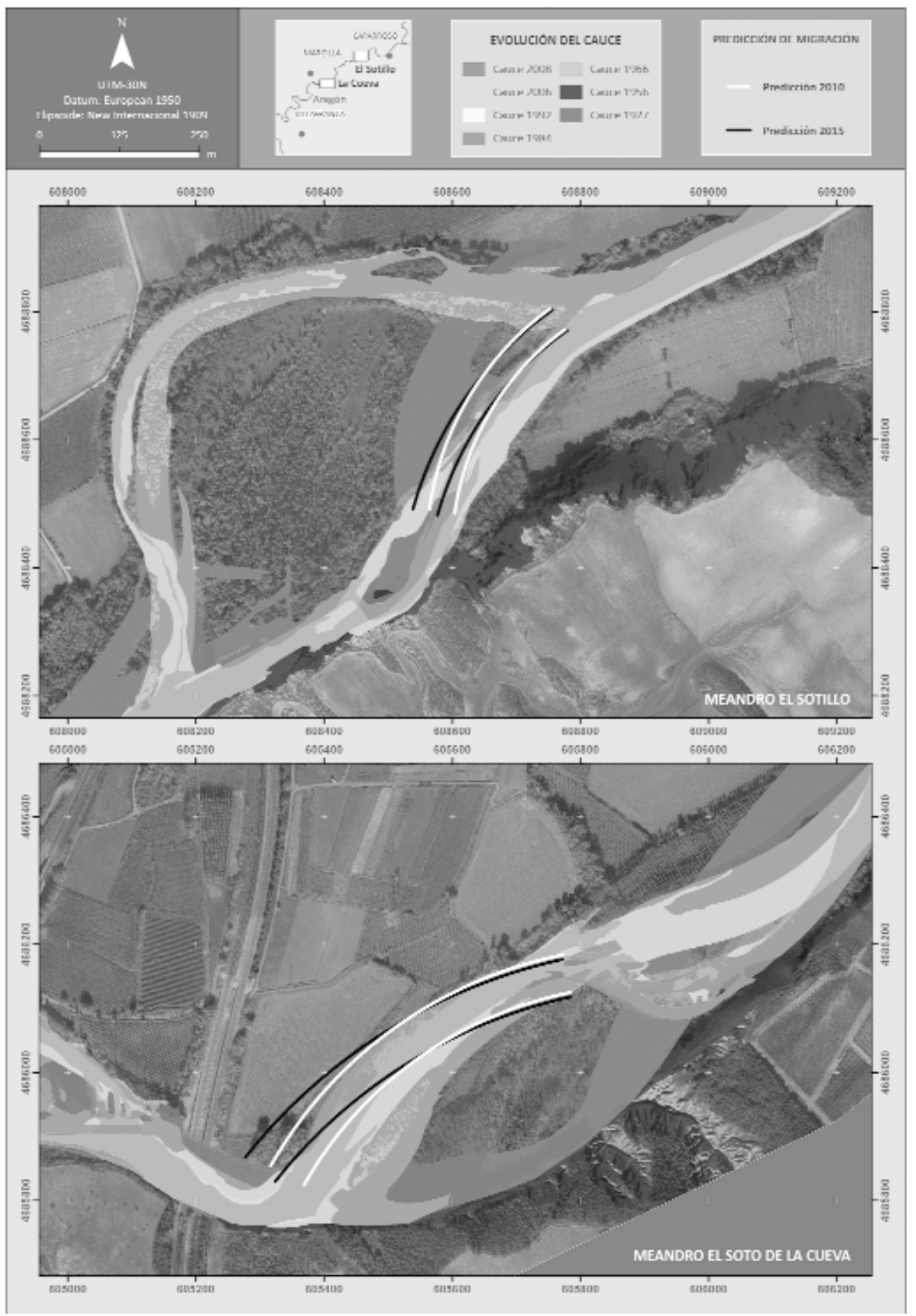

Figura 8. Dinámica de los meandros de El Sotillo y Soto de la Cueva y predicción de su migración. 
Ebro (18,9 m) por Ollero (2010). Sin embargo, en el Ebro la dinámica lateral fue totalmente eliminada desde 1981, mientras en el río Aragón se mantiene cierta capacidad de cambio, al quedar algunas orillas cóncavas no defendidas. El análisis de detalle en los meandros no defendidos de El Sotillo y Soto de la Cueva confirma que la dinámica es posible si no hay defensas que estabilicen las orillas. En cambio en el Arga la migración del cauce y las superficies movilizadas son inapreciables desde 1984 por la canalización efectuada. En suma, las defensas locales cuentan con un papel mucho más importante que las presiones de cuenca (embalses) en la estabilización del trazado del cauce, mientras el efecto de los embalses se manifiesta considerablemente en la drástica reducción de las superficies de sedimentos sin colonizar.

Para recuperar el patrimonio geomorfológico de unos cauces dinámicos es necesario ampliar el espacio fluvial y eliminar sistemas defensivos, en casos en que no supongan un riesgo directo a la población. De esta forma se reducirían considerablemente los efectos de crecida por la propia laminación en esos espacios, se ampliaría la dinámica geomorfológica y con ello se propiciaría la formación de nuevos biotopos y morfologías fluviales, incrementándose la diversidad biológica y geomorfológica.

\section{Conclusión}

Comprobado el proceso de estabilización y simplificación de la dinámica hidrogeomorfológica de los cursos bajos de los ríos Arga y Aragón, ofrece un ejemplo claro de la evolución que están sufriendo muchos ríos afectados por regulación hídrica e inmovilización geomorfológica.

El análisis, cuantificación e interpretación de la dinámica fluvial con la metodología empleada han permitido comparar las respuestas fluviales a los impactos sufridos. La dinámica expuesta constituye un indicador fundamental para establecer en el futuro posibles medidas de gestión del riesgo, ordenación del espacio fluvial y conservación de la alta calidad hidromorfológica. En el área de estudio sería recomendable proteger la dinámica geomorfológica actual con medidas conservacionistas, así como establecer un espacio de movilidad fluvial para mejora ambiental y para reducción de riesgos en sustitución de las defensas tradicionales. 


\section{Agradecimientos}

Este artículo incluye datos tomados para el "Estudio de alternativas de actuación de restauración de ríos y defensa frente a inundaciones en la zona de confluencia de los ríos Arga y Aragón: Estudio geomorfológico" realizado bajo convenio firmado entre Euskoiker y Gestión Ambiental, Viveros y Repoblaciones de Navarra, S.A. y financiado por el Departamento de Desarrollo Rural y Medio Ambiente del Gobierno de Navarra. Agradecemos a los citados organismos la cesión de la información cartográfica y de fotografía aérea.

\section{Referencias}

Ben Ayed, S. (1993) Bases physiques pour l'aménagement de l'espace riverain $d u$ cours inférieur de la rivière Aragón (tronçon de méandres libres entre la localité de Carcastillo et la confluence de la rivière Arga - Navarre). Diploma Master de Ordenación Rural y Medio Ambiente, Centro Internacional de Altos Estudios Agronómicos Mediterráneos, Zaragoza.

Bescós, A. (2003) Las inundaciones en el río Arga: estudio bidrogeomorfológico. Departamento de Geografía. Universidad de Alcalá. Tesis doctoral inédita. 407 p + cartografía y anexos

Bescós, A. y Camarasa, A.M. (2004) La creciente ocupación antrópica del espacio inundable y el aumento de la vulnerabilidad en las poblaciones del bajo Arga (Navarra). Boletín de la Asociación de Geógrafos EspañolesA.G.E., 37: 101-117.

Cabezas, A., Comín, F.A., Beguería, S. y Trabucchi, M. (2009) Hydrologic and landscape changes in the Middle Ebro River (NE Spain): implications for restoration and management. Hydrology and Earth System Sciences, 13: 1-12.

Downward, S.R., Gurnell, A.M. y Brookes, A (1994) A methodology for quantifying river channel change using GIS. In: Oliva, L.J., Loughran, R.J., Kesby, J.A. (eds.) Variability in stream erosion and sediment transport, 449-456, Wallingford, International Association of Hydrological Sciences.

El Moujahid, A. (1993) Bases fisicas para la ordenación del espacio ribereño del río Arga. Tramo de meandros libres entre el meandro del Arquillo y Peralta. Diploma Master de Ordenación Rural en función del Medio Ambiente, Centro Internacional de Altos Estudios Agronómicos Mediterráneos, Zaragoza.

Hickin, E.J. y Nanson, G.C. (1984) Lateral migration rates of river bends. Journal of Hydraulic Engineering 110(11): 15571567.

Jimeno, A. (1993) El río Arga (tramo PeraltaFunes): dinámica fluvial. Memoria de licenciatura, Dpto. Geografía y Ordenación del Territorio, Universidad de Zaragoza, $245 \mathrm{p}$.

Jimeno, A. (1996) El sistema cauce-riberas en el curso bajo de los ríos Arga y Aragón. Estudio ecogeográfico. Tesis doctoral, Dpto. Geografía y Ordenación del 
Territorio, Universidad de Zaragoza, 688 p. + anexos.

Lagasse, P.F.; Spitz, W.J.; Zevenbergen, L.W. y Zachmann, D.W. (2004) Handbook for predicting stream meander migration. Washington, National Cooperative Highway Research Program, 66 p. + appendix.

Magdaleno, F. (2011) Evolución hidrogeomorfológica del sector central del río Ebro a lo largo del siglo XX. Implicaciones ecológicas para su restauración. Tesis doctoral. E.T.S. Ingenieros de Montes, Universidad Politécnica de Madrid.

Ollero, A. (1992) Los meandros libres del Ebro medio (Logroño-La Zaida): geomorfología fluvial, ecogeografía y riesgos. Tesis doctoral. Departamento de Geografía y Ordenación del Territorio, Universidad de Zaragoza, 1.138 págs. + cartografía.

Ollero A. (2010) Channel changes and floodplain management in the meandering middle Ebro River, Spain. Geomorphology, 117: 247-260.

Uribelarrea, D. (2008) Dinámica y evolución de las llanuras aluviales de los ríos Manzanares, Jarama y Tajo, entre las ciudades de Madrid y Toledo. Tesis doctoral. Dpto. de Geodinámica, Universidad Complutense de Madrid. 